\title{
Green Bio composites For Food Packaging
}

\author{
H.N. Salwa, S.M. Sapuan, M.T. Mastura, M.Y.M Zuhri
}

\begin{abstract}
Petroleum-based synthetic polymers are mostly used for packaging materials for their advantageous features such as flexibility, lightness and transparency. However, the waste caused by the increasing usage has led to serious environmental impacts. There are many packaging products claimed as 'green' material in the market but, they are not fully from natural renewable resources. Most biocomposites materials comprised only either the matrix or fiber/filler from natural renewable resources, but still blended with another synthetic compound. Thus, green biocomposites which composed of fully biodegradable natural fibers and biopolymer matrix would be a great alternative. It can be naturally degraded and completely return to the environment safely after usage. The main shortcomings of biopolymer are their inadequate of mechanical and barrier properties in product application. Yet, the embedding reinforcing fibers or fillers would help in improving the final properties of the composites.
\end{abstract}

The intention of this review is to present the latest development of green biocomposites research and its application for food packaging. It is also proposed to provide critical information that covers around properties of green biocomposites, types of available biopolymers and natural fibers, including their manufacturing techniques. Furthermore, the economic circumstances and forthcoming trend of these materials in food packaging industry would also be reviewed.

Index Terms: Green biocomposites; biodegradable food packaging; bio-based packaging; sustainable packaging

\section{INTRODUCTION}

Packaging plays a significant role in every aspect of our daily life, and it has shown continuous increment. Common petroleum-based polymer materials for plastics packaging are polypropylene (PP), polyester (PET), polyethylene (PE) and

Revised Manuscript Received on July 05, 2019.

H.N. Salwa, Institute of Tropical Forestry and Forest Products (INTROP), Universiti Putra Malaysia (UPM), Serdang, Selangor, 43400, Malaysia

S.M. Sapuan, Advanced Engineering Materials and Composite Research Centre, Department of Mechanical and Manufacturing Engineering; and Institute of Tropical Forestry and Forest Products (INTROP), Universiti Putra Malaysia (UPM), Serdang, Selangor, 43400, Malaysia. Corresponding author.Email: sapuan@upm.edu.my

M.T. Mastura, Faculty of Mechanical and Manufacturing Engineering Technology, Universiti Teknikal Malaysia Melaka (UTem), Hang Tuah Jaya, Durian Tunggal, Melaka, 76100, Malaysia.

M.Y.M Zuhri, Department of Mechanical and Manufacturing Engineering, Faculty of Engineering, Universiti Putra Malaysia (UPM), Serdang, Selangor, 43400, Malaysia. polystyrene (PS). Most of these traditional plastics are recyclable, however many countries encounter technical and economic constraints to recycle these plastic packaging waste [1], [2]. The lack of biodegradability, petroleum-based plastics triggered significant waste management issues and contamination to the freshwater systems and global habitats [3]. Most of the used plastic packaging, especially single use packaging from food packaging end up in landfills or become trash on land and water streams; and finally, into the ocean [1], [4], [5]. In 2015, approximately 6300 million metric tonne (Mt) of plastic waste was generated globally which only around $9 \%$ had been recycled, $12 \%$ was incinerated, and most of it $(79 \%)$ was piled up in landfills or scattered in the ecosystem [3].

Even though recycling rate for plastic waste is projected to increase up to $40 \%$ by year 2050, the amount of plastics waste gathered in landfills and natural environment will still high of roughly $12,000 \mathrm{Mt}$. It is also predicted that there will be 1 tonne of plastic for every 3 tonnes of fish in the ocean by 2025 and by the year 2050, there will be more plastics than fish [6]. Parallelly, the continuing dependency on petroleum will cause depletion and thus will increase the costs of raw materials [7].

Consumers and retailers, in combination with the government's latest regulations on environment forcing the development of "greener" packaging products as an alternative. Sustainable growth of the packaging industry needs robust renewable materials to be fully developed [7]. Bio-derived materials now are getting distinct attention for its advantages of reduced carbon footprint compared to conventional plastics [5], [7]- [9].

Bioplastics aim to replicate the life cycle of biomass which includes preservation of fossil resources, and water and $\mathrm{CO} 2$ pro-duction as shown in Fig.1. Fascinatingly, a report on sustainable design proposed a similar circular model which emphasis on sustaining material quality in biological and technical cycles (Fig. 2).

In this cycle systems, outputs from other steps inside the circular system form inputs for the other steps. The re-searches added that fully bio-based packaging materials does not leave the biological systems because they ultimately coming back to the environment after post-use cycles where landfilling does not occur as part of the systems.

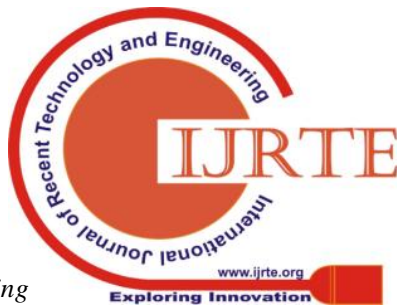




\section{Green Bio composites For Food Packaging}

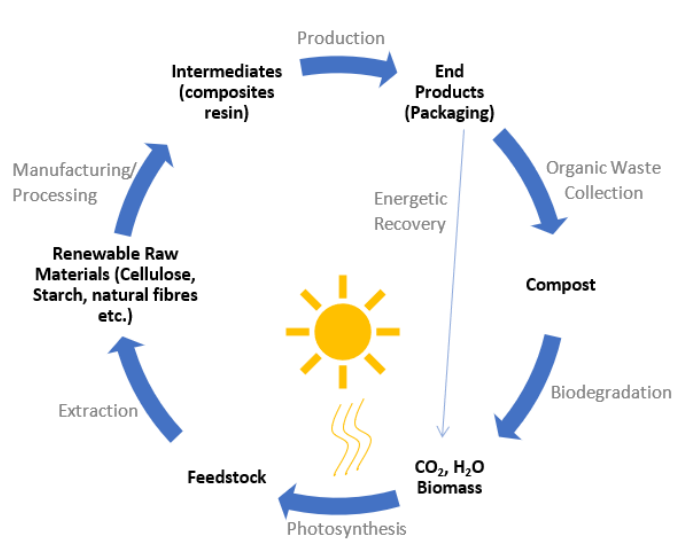

Fig. 1: Life cycle of bioplastic packaging [10]

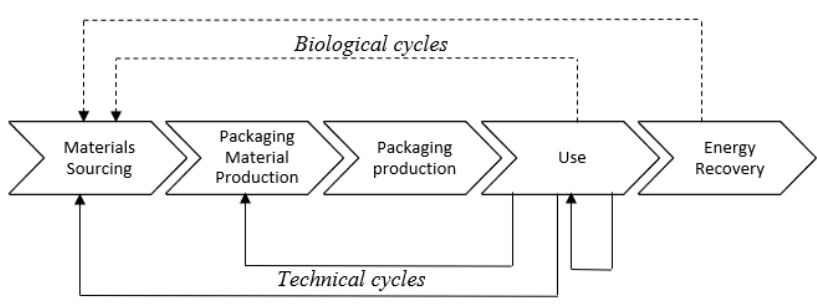

Fig 2: Circular Packaging system- Sourcing, Production, Use and Post-Use in biological and technical cycles [11]

It is important to note that 'green' plastic packaging available in market may not be accurate in terms of its renewability. The materials used may comply with the biodegradability standards which means it can be degraded by microorganisms in an ap-propriate circumstances of bio-active environment [2]. Nevertheless, these materials can also mean synthetics materials. In most bio-based polymer composites, either the matrix or the fiber/filler is drawn from natural renewable resources, but still blended with another synthetic compound [9], [12], [13]. Fully biodegradable biopolymer composites with both natural fibers and biopolymer matrix as the constituents are termed "green biocomposites". Green biocomposites seems to be great material alternatives for short life application and afterwards can be naturally degraded and completely returned to the environment safely[9], [14]-[18].

\section{BIOCOMPOSITES}

Composites are compounds composed of two or more constituents' materials as the matrices and fibers. These materials when blended together are stronger compared to individual materials by themselves. More environmentally friendly composites materials are getting higher attention in the recent years and researches have revealed that biocomposites are materials with great potential as a solution in addressing needs of sustainability aspect in product design [16], [19]. Al-Oqla et al. (2017) stated in their report that biocomposites not only have advantages for its significant performance in mechanical properties, but also give several processing advantages. Other benefits are the low cost, availability, light weight, more environmentally friendly with recyclability and degradability features [9].
"Biocomposites" are composites with either the matrix or fiber, or both matrix and fiber, are derived from biological resources. Researches split biocomposites into three main groupings: 1) natural fiber reinforced non-biodegradable petroleum derived polymers; 2) synthetic fibers reinforced bio-based polymers; and 3) bio-based polymers reinforced by natural fibers [9], [20]. The first two categories are not completely environmentally friendly because one of the constituents is petroleum derived. The third category where both constituents are derived from renewable resources or termed as "green biocomposites" are believed to be the best alternative to address environmental concerns for consumer product application [9].

The properties of green biocomposites can be customized according to specific type of applications. This is done by a proper selection of fibers or fillers, biopolymer matrix, additives and manufacturing methods according to the application requirement. Ramesh et al. (2017) specified that the vital considerations in forming green biocomposites are: 1) fiber selection which include type, harvest time, extraction method, aspect ratio, treatment and fiber content, 2) biopolymer matrix selection, 3) interfacial strength, 4) fiber dispersion, 5) fiber orientation, 6) manufacturing process, and 7) porosity [21]. Other than that, there are four most important criteria in designing green biocomposites with stable mechanical properties. There are: (i) a homogeneous dispersion of the fibers; (ii) An excellent interaction between the matrix and the fibers; (iii) a matrix with low porousness; (iv) an optimized percentage of reinforcing fibers [21], [22]. Table 1 summarized few recent studies on green Biocomposites. 
Table 1: Recent studies on green biocomposites

\begin{tabular}{|c|c|c|c|c|c|}
\hline & Scope of study & Year & Biopolymer & Natural Fiber/ Filler & Ref. \\
\hline 1 & $\begin{array}{l}\text { Effect on mechanical properties, water } \\
\text { absorption behaviour and thermal properties of } \\
\text { biocomposites with different amounts of fibers }\end{array}$ & 2013 & Sugar palm starch & Ijuk (sugar palm fiber) & {$[23]$} \\
\hline 2 & $\begin{array}{l}\text { Effects on surface morphology, tensile, flexural, } \\
\text { thermal and biodegradable properties of the } \\
\text { biocomposites with different fiber content (5-30 } \\
\text { wt } \% \text { ) and fiber treatment }\end{array}$ & 2014 & Polylactic acid (PLA) & Coir & [24] \\
\hline 3 & $\begin{array}{l}\text { Fibers derived from solid food by-products as } \\
\text { fillers in PHBV and characteristics/ properties of } \\
\text { the composites and its constituents }\end{array}$ & 2015 & $\begin{array}{l}\text { Poly(3-hydroxybutyrate-co-vale } \\
\text { rate) (PHBV) }\end{array}$ & $\begin{array}{l}\text { Wheat straw, brewing } \\
\text { spent grains and olive mills }\end{array}$ & {$[25]$} \\
\hline 4 & $\begin{array}{l}\text { Effects on structural, thermal, mechanical and } \\
\text { disintegration properties of plasticized } \\
\text { electrospun PLA-PHB biocomposites with } \\
\text { chitosan and catechin microfillers }\end{array}$ & 2016 & $\begin{array}{l}\text { Polylactic acid (PLA) blended } \\
\text { with Poly(hydroxybutyrate) } \\
\text { (PHB) }\end{array}$ & Chitosan and catechin & [26] \\
\hline 5 & $\begin{array}{l}\text { Flexural behaviour and morphologic and } \\
\text { thermal characteristics of biocomposites }\end{array}$ & 2017 & PLA and pine resin blend & Açaí palmacea fiber & [27] \\
\hline 6 & $\begin{array}{l}\text { Thermal, mechanical, and physical properties of } \\
\text { seaweed/sugar palm fiber reinforced } \\
\text { thermoplastic sugar palm Starch/Agar hybrid } \\
\text { composites }\end{array}$ & 2017 & $\begin{array}{l}\text { Seaweed/ thermoplastic sugar } \\
\text { palm starch agar (TPSA) }\end{array}$ & Sugar palm fiber (SPF) & [28] \\
\hline 7 & $\begin{array}{l}\text { Effect of the incorporation of rich fiber lentil } \\
\text { flour in thermoplastic starch films on the } \\
\text { structure, physicochemical properties and } \\
\text { biodegradability }\end{array}$ & 2018 & Cassava starch & Lentils & [29] \\
\hline 8 & $\begin{array}{l}\text { Barrier performance to water, thermoforming } \\
\text { ability and disintegration in controlled } \\
\text { composting conditions of the composites }\end{array}$ & 2018 & Poly(hydroxybutyrate) (PHB) & $\begin{array}{l}\text { Ligno-cellulosic wastes - } \\
\text { almond shell, rice husk and } \\
\text { seagrass }\end{array}$ & {$[30]$} \\
\hline 9 & $\begin{array}{l}\text { Reinforcement mechanism of bamboo cellulose } \\
\text { nano-whiskers (BCNW) in PLA composites }\end{array}$ & 2018 & Polylactic acid (PLA) & $\begin{array}{l}\text { Cellulose nano-whiskers } \\
\text { (CNW) }\end{array}$ & [31] \\
\hline
\end{tabular}

\section{A. BIOPOLYMER MATRIX}

The term "bio" is often used to indicate that the materials are biodegradable materials in topics of polymer, composites and packaging. However, it is also applied to indicate materials derived from renewable natural resources [7]. There are biodegradable polymers which are produced from petroleum-based and they are termed as green polymeric matrices too [9]. The European Bioplastics Association gives wide definition of 'bioplastics' which can be distinguished by three conditions: 1) bio-derived and biodegradable or compostable, 2) fossil fuel-derived and biodegradable, or 3) bio-derived and non-biodegradable [7]. In general, not all biopolymers are biodegradable, and biodegradable polymers does not necessarily mean bio based. In this paper, "bio" in the term "biopolymers" is defined as bio-based which means the materials are derived from renewable resources and are biodegradable. The prime environmental attribute of biopolymers is their biodegradability and compostability. There are several approaches in sorting biopolymers such as their corresponding chemical composition, synthesis method and according to their economic importance or application areas. Each classification provides diverse and valuable data for certain research area and application [7]. Generally, many researches divide biopolymers into three main groups based on their production process: 1) simply extracted straightforward from natural materials like polysaccharides (e.g. cellulose, starch, chitin), lignins, proteins, and lipids; 2) made through chemical synthesis from renewable bio-derived monomers such as polylactide (PLA); 3) materialized by microorganisms or genetically transformed by bacteria which includes polyhydroxyalkanoates (PHA), polyhydroxybutyrate (PHB) and copolymers of hydroxybutyrate and hydroxyvalerate (PHBV) [7], [32]. However, Saba et al. (2017) simply divide biopolymers into two main categories i.e. those derived from living organism and those need to be polymerized. This categorization is illustrated in Fig. 3 [17].

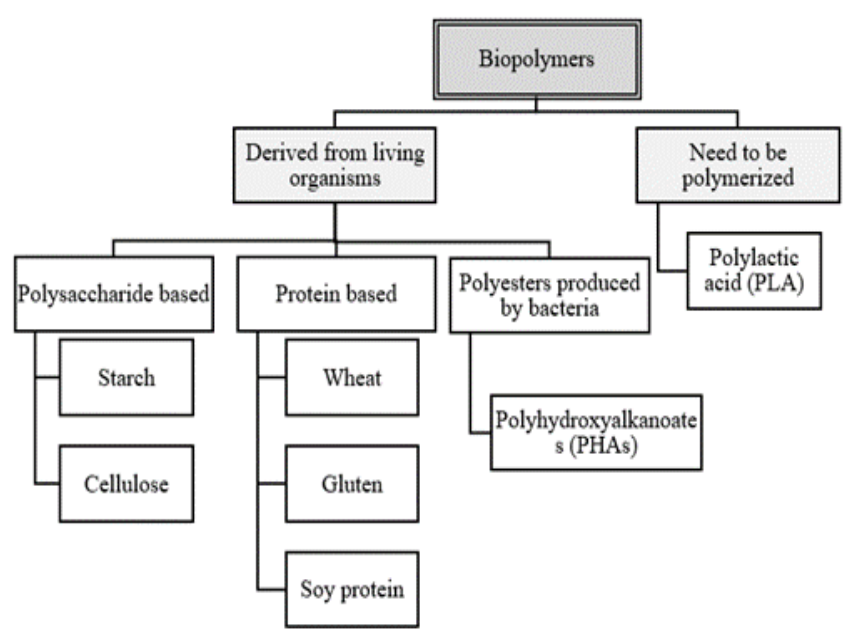

Fig 3: Biopolymer categorization [17]

Biopolymers present as matrix in biocomposites influence the properties of green biocomposites according to its application. Biopolymer like other polymer matrix, it supports and locks the 
reinforcing fibers together. Biopolymer matrix transfers load and stress to the reinforcement and provides protection from environmental and chemical damage to the composite [33], [34]. Starch, cellulose, pectin, gluten, gelatine, soy protein, polylactide (PLA), polyhydroxy-butyrate (PHB) are the most studied biopolymer [32]. Meanwhile, polylactic acid (PLA) is available commercially as an alternative to conventional synthetic polymers for industrial plastic application. PLA has high mechanical properties and good processability, however, its limitations such as brittleness, low impact strength, and low thermal resistance, are similar with the other biopolymers. In order to make them suitable in various applications, the mechanical properties of biopolymer need to be enhanced by using reinforcement agent [35]. Performance of biopolymer's mechanical properties is interpreted in graph as shown in Fig. 4. Barrier properties are important for materials to be used in packaging and gathered data on barrier properties of some biopolymers from recent reports are presented in Table 2. Biopolymer alone has poor mechanical and barrier properties to be applied for product application and impregnated natural fiber as reinforcement proven to be an excellent alternative solution.

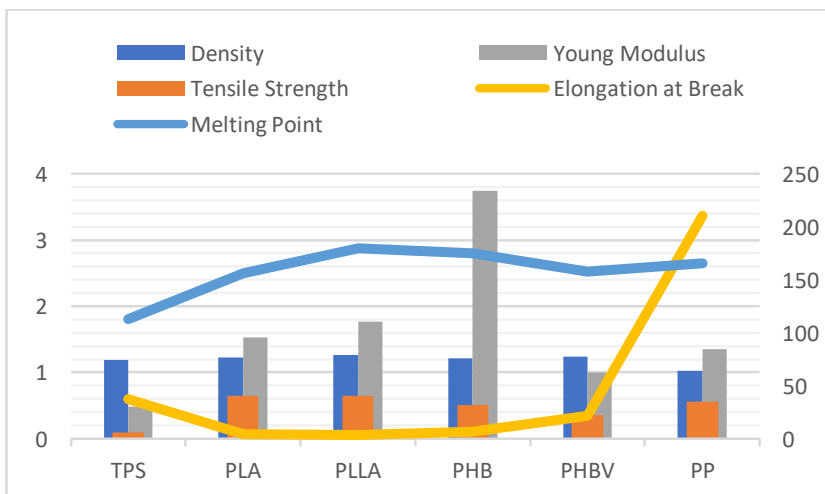

TPS: Thermoplastic Starch; PLA: Polylactic acid; PHB: Polyhydroxybutyrates PHBV: Poly(hydroxybutyrate-co-hydroxyvalerate; PP: poly propylene

Fig. 3: Performance of biopolymer's mechanical properties [13]

Table 2: Barrier properties of different biopolymer [36]-[40]

\begin{tabular}{|c|c|c|c|c|}
\hline & $\begin{array}{l}\text { Water Vapour } \\
\text { Transmission } \\
\text { Rate (WVTR) }\end{array}$ & $\begin{array}{l}\text { Water vapour } \\
\text { Permeability }\end{array}$ & $\begin{array}{l}\text { Oxygen } \\
\text { Transmission } \\
\text { Rate (OTR) }\end{array}$ & $\begin{array}{l}\text { Oxygen } \\
\text { Permeability }\end{array}$ \\
\hline $\begin{array}{l}\text { Polylactic } \\
\text { acid (PLA) }\end{array}$ & $\begin{array}{l}15.3 \pm 0.04- \\
23.1 \pm 0.5 \text { g.m- } \\
{ }^{2} . \text { day }^{-1}\end{array}$ & $\begin{array}{l}1.34 \mathrm{E}-14 \mathrm{~g} \cdot \mathrm{m}- \\
{ }^{2} . \mathrm{day}^{-2}\end{array}$ & $\begin{array}{l}56.33 \pm 0.12- \\
76.6 \pm 6.5 \mathrm{cc} \cdot \mathrm{m}- \\
{ }^{2} \text {.day }\end{array}$ & $\begin{array}{l}4.33 \mathrm{E}-18 \pm 1.0 \mathrm{E}-19 \\
\mathrm{~kg} \cdot \mathrm{m} \cdot \mathrm{m}-2 \mathrm{~s}-1 . \mathrm{Pa}^{-1}\end{array}$ \\
\hline $\begin{array}{l}\text { Thermoplast } \\
\text { ic Starch } \\
\text { (Corn) }\end{array}$ & $\mathrm{NA}$ & $\begin{array}{l}(15.52 \pm 0.09) 10^{13} \\
\mathrm{~kg} \cdot \mathrm{mPa}^{-1} \cdot \mathrm{s}^{-1} \cdot \mathrm{m}^{-2}\end{array}$ & $\mathrm{NA}$ & $\begin{array}{l}(41.00 \pm 2.3) 10^{18} \\
\mathrm{~m} 3 \cdot \mathrm{mPa}^{-1} \cdot \mathrm{s}^{-1} \cdot \mathrm{m}^{-2}\end{array}$ \\
\hline Yam Starch & $\mathrm{NA}$ & $\begin{array}{l}(1.81) 10^{-10} \mathrm{~g} \cdot \mathrm{m}^{-1} \mathrm{~s} \\
{ }^{1} \cdot \mathrm{Pa}^{-1}\end{array}$ & $\mathrm{NA}$ & $\mathrm{NA}$ \\
\hline $\begin{array}{l}\text { Polyhydroxy } \\
\text { butyrate }\end{array}$ & $\mathrm{NA}$ & $\begin{array}{l}(7.88 \pm 1.11) 10^{15} \\
\mathrm{~kg} \cdot \mathrm{m} \cdot \mathrm{m}^{-2} \cdot \mathrm{Pa}^{-1} \cdot \mathrm{s}^{-1}\end{array}$ & $\mathrm{NA}$ & $\begin{array}{l}(7.94 \pm 0.24) 10^{19} \\
\mathrm{~m}^{3} \cdot \underline{\underline{\mathrm{m} \mathrm{m}^{-2} \mathrm{~s}^{-1}} \cdot \mathrm{Pa}^{-1}}\end{array}$ \\
\hline
\end{tabular}

\section{B. NATURAL FIBER}

The term "natural fiber" is used to describe many types of naturally produced fibers. These fibers could be from plants or animals or derived from some minerals. In this paper, the term 'natural fiber' that is commonly discussed in packaging is referred as 'plant fibers' or sometimes termed as 'lignocellulosic fibers' or 'cellulosic fibers' [7], [41]. Similar to synthetic fibers like carbon or glass fiber, natural fibers reinforced composites materials and controlled the unique properties of the final materials for better stiffness and adequate strength [7], [42]-[44].

Natural fiber type can be categorized based on its origin in plants i.e. bast/stem, leaves, fruit, grass/ reed, wood or directly from a tree like ijuk fiber (sugar palm fiber) or arenga piñata which covering the trunk of the sugar palm tree [46]. In general, natural fibers which are abundant and renewable can be classified according to their origin in plants as depicted in Error! Reference source not found.5. The properties of natural fibers or cellulosic fibers are very much influenced by their chemical composition and morphological factors such as internal fiber structure, microfibril angle and cell dimensions. These factors can vary based on location of fiber in the plant, geographical location of the plants being planted, as well as between different type of plants [7], [46].

In the environment viewpoint, manipulating natural fibers over conventional synthetic fibers are favorable because of their bio-degradability, renewability, recyclability and non-toxic nature [33], [41]. Their easy availability, low cost and their properties such as low density, light weight, acceptable specific strength and stiffness are attractive enough to provide excellent reinforcement alternatives to man-made fibers [1], [33], [45]. Plant fibers are also preferred as reinforcement in composites to reduce tool wear in machining, non-abrasiveness and easy to manufacture [21], [33].

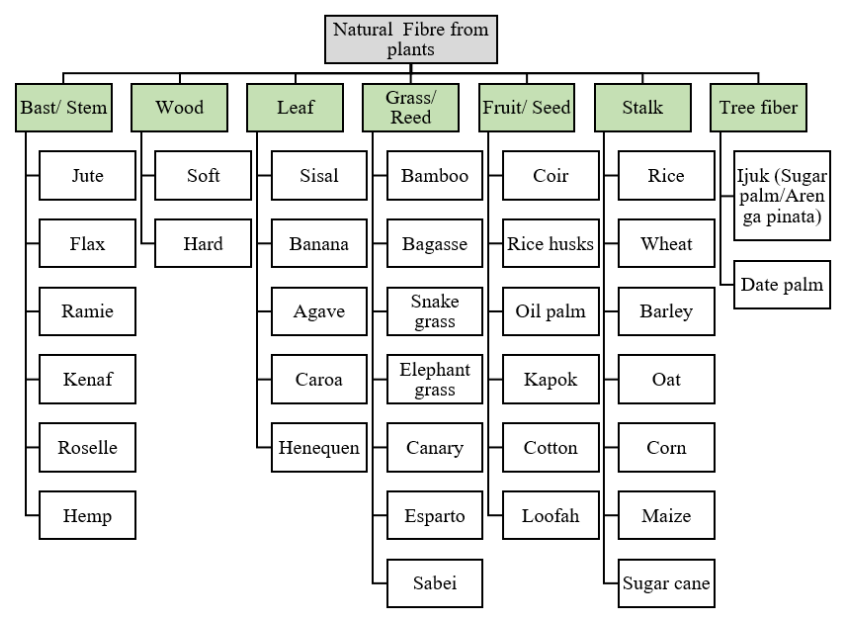

Fig. 4: Classification Natural or Plant Fiber based on its origin in plants [5], [21], [46]

Mechanical properties of composites that are reinforced by natural fiber can be contributed by many factors including fiber-matrix adhesion, the volume fraction of the fibers, the fiber aspect ratio (1/d), and the fiber orientation [1]. Zhou et al. (2017) reported that critical requirement to select natural fibers in green biocomposites fabrication are; i) a higher degree of polymerization, ii) cellulose content, and iii) a lower microfibril angle. These attributes could yield higher tensile modulus and strengthen composites materials [17]. Most studies however agreed that the key in

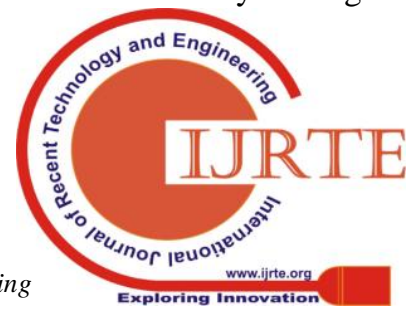


designing green biocomposites is the fiber-matrix interfacial adhesion [9], [17], [21], [32], [33], [35], [48].

Although many advantages of natural fiber have been recognized, its drawback of extremely sensitive on moisture and effortlessly absorb water from the surrounding environment has been always be the major concern [9], [41]. Moisture absorption would cause them to swell and produce unstable measurements which would initiating altered mechanical and physical properties of the composites. Siakeng et al. (2018) stated that there are three mechanisms of water absorption in fiber composites namely diffusion method, capillary flow and composites moisture content. Moisture content is the water stored in the micro-cracks present in both polymer and natural fiber and this contribute to water absorption of composites [35]. This unwanted hydrophilic characteristics of natural fiber caused them to have low microbial resistance and decay easily too. Most importantly this weaken the interfacial adhesion between the fiber and the matrix [21], [49]. However, moisture absorption in biocomposites could also contributed by other factors such as fiber fraction, viscosity of matrix, voids, temperature and humidity and [35].

Performance of natural fiber reinforced biocomposites can caused a great challenge in product application. This includes; 1) its bad wettability, 2) inadequate bonding, 3) fiber/matrix interface degradation, and 4) fiber deficit during the manufacturing process [1], [21], [45]. In the recent years, there a lot of studies being done to enhance the adhesion between the fiber and matrix and one of the approaches is application of chemical "coupling" agents. Chun and Husseinsyah (2017) studied on green coupling agent (GCA) obtained from virgin coconut oil (GCA-C) to improve interfacial adhesion in composites. GCA-C is a kind of glycidyl fatty acid ester which is reactive to natural fiber or filler. The results shown that the composites' tensile strength and tensile modulus increased with the increasing of the GCA content. Elongation at break of the composites also increased at $5 \mathrm{wt} \%$ of GCA content [50]. Another study used maleate and silane coupling agents (MAPW, Si69 and VTMS) on bulk composites of wood plastics (WPC). They discovered from the Scanning Electron Microscopy (SEM) images that the treated WPC has improved compatibility between the constituents which signifies better interface, wettability of wood flour, and resin penetration [51].

Surface modifications on natural fibers is another method used to improve their adhesion with the matrices. Plasma treatment is a physical technique to modify the surface of natural fibers and utilize to improve the mechanical properties of natural fibers [52]. Surface modification of natural fiber using biological processes done by Cruz and Fangueiro (2016) where cellulose nanofibrils were used as substrates and deposited on the surface of sisal and hemp fibers during the fermentation process of bacterial cellulose. The results showed that $5-6 \%$ bacterial cellulose on the natural fiber surface gives significant improvement in interfacial adhesion with biopolymer matrices such as polylactic acid (PLA) [52]. This leads to the development of a biocomposites with improved fiber-matrix interfacial bonding.

Pre-treatment process of fiber is also vital in determining the final interfacial bonding properties to permit successful stress transfer of the resultant composites. Despite this, there are also other factors which influence the quality of natural fibers. Error! Reference source not found. illustrates possible factors of natural fiber process until supplied to manufacturer which may affect the quality of natural fibers as reinforcement in composites.

\begin{tabular}{|c|c|c|c|}
\hline Plant growth & Harvest & & Supply \\
\hline $\begin{array}{l}\text { - Plant species } \\
\text { - Crop cultivation } \\
\text { - Crop location } \\
\text { - Location of fiber } \\
\text { in plant } \\
\text { - Local climate }\end{array}$ & $\begin{array}{l}\text { Ripeness of fiber } \\
\text { (cell wall } \\
\text { thickness, } \\
\text { coarseness of } \\
\text { fibers) }\end{array}$ & $\begin{array}{l}\text { - Decortication } \\
\text { process } \\
\text { - Type of retting } \\
\text { method }\end{array}$ & $\begin{array}{l}\text { - Transportation } \\
\text { conditions } \\
\text { - Storage } \\
\text { conditions } \\
\text { - Age of fiber (after } \\
\text { extraction) }\end{array}$ \\
\hline
\end{tabular}

Fig. 5: Contributing factors on quality of fibers at each stage to be the reinforcement agent in composites [21].

Fiber extraction process depends on the origin of fiber in the plants. For bast or stem fibers like hemp fibers, they must get through the retting process and decortication process Retting process separates inner and outer stem of plant and the separated outer plant form a fiber, meanwhile decortication process is to produce single fibers from the plant strand fibers [21]. In mechanical extraction processing of fibers, raw fibers undergo breaking, scutching and hackling process to get long fiber [53], [54]. Another process to produce strand fibers or wood chips to individualized fibers is called pulping. There are mechanical pulping and chemical pulping procedure to remove the lignin from strands and wood strips to produce individualized fiber. Later, the process of bleaching and mechanical beating are performed [21]. Interestingly, ijuk fiber does not need to undergo this extraction process because of its natural fiber form. Huzaifah et al. (2017) in their study, basically washed, air dried for 24 hours and afterwards dried in the oven at $85{ }^{\circ} \mathrm{C}$ for another 24 hours to prepare the fiber [47]. Other parameters in producing the fibers that would influence the final properties of green biocomposites are volume fraction of the fibers, fiber aspect ratio, and also the orientation of fiber [21]. Properties of natural fiber including $i j u k$ fiber and conventional fibers are compiled in Error! Reference source not found. 
Table 3: Physical, mechanical and chemical properties of most studied natural fibers [21], [33], [46], [55], [56]
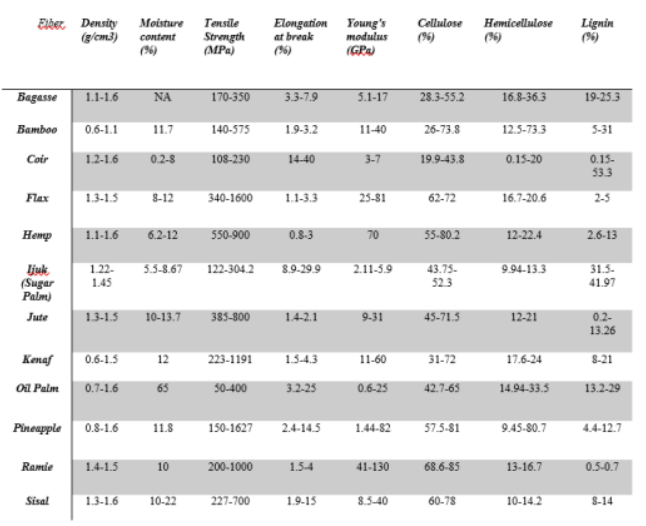

\section{BIONANOCOMPOSITES}

Nanotechnology brings opportunities to improve the perfor-mance of biocomposites. Nano-clay (layered silicates), cellulose nanowhiskers, ultra-fine layered titanate, and carbon nanotubes are among nano-reinforcements being developed [32]. Nano-crystalline cellulose is appealing for its variety of application for its strength of "better than steel and stiffer than aluminum" [21]. Nanocrystalline cellulose not only could function as 'filler' in a matrix but could enhanced the properties of the composites. The performance is improved at the same time enhanced its durability, value, and service-life without compromising sustainability. Packaging sector would be very interested in nano-scaled cellulose fibers to produce biocomposites films with improved mechanical and barrier properties, and excellent transparency. It would also possible to produce biocomposites packaging materials with additional functional properties such as transparency, biodegradability, specific surface properties and enhanced gas barrier and heat sealability [7].

Nanocellulose materials have a high specific surface area with rich hydroxyl groups and nanoscale morphology which contribute to higher strength, lower density and transparency; better barrier properties, and lower thermal expansion too. These make them perfectly suitable for packaging films [1]. Nanocomposites exhibit remarkable improvement in materials properties when small percentage of silicate content $(\leq 5 \%)$, comparing with pristine polymer or conventional micro- and macro-composites. They were found to have higher modulus, stronger, improved heat resistance, and decreased moisture and gas permeability, and flammability [32]. There are two classifications of nanocellulose namely, cellulose nanocrystals (CNCs) and cellulose nanofibrils (CNFs). CNCs are prepared by treating cellulosic fiber with sulfuric acid or hydrochloric acid and a mechanical process afterwards, normally sonication. CNCs are cellulose crystals with rod-like appearance with width of 5 to $70 \mathrm{~nm}$ and length between $100 \mathrm{~nm}$ and several micrometers [1], [21]. CNCs have excellent mechanical properties, optical properties, high aspect ratio, and well-defined dimensions and thus have possibilities for reinforcements in packaging films [57]. $\mathrm{CNCs}$ have a highly crystalline nature and if used as fillers in composites by increasing both crystallinities, the pathway for diffusion of gas molecules can improve the oxygen barrier properties of biocomposites packaging materials [1]. On the other hand, CNF or sometimes termed as NFC (nanofibrillated cellulose) or MFC (microfibrillated cellulose) typically have finer fibril size and generally a lower length. CNFs are fabricated by treating cellulosic fibers in mechanical processes such as homogenizers, microfluidizers, and micro-grinders. These methods require a huge amount of energy input and can damage both fibril length and yield. CNFs have lower crystallinity and higher aspect ratio and caused tortuosity increment and entanglements which provide excellent oxygen barrier properties to the pure CNFs films [1]. The report also highlighted that CNFs can be used as filler in nanocomposites to increase the oxygen and grease barrier properties that have fewer and smaller pores to prevent grease penetration and are tough enough to with-stand various defects development like cracks [1]. Furthermore, Ramesh et al. (2017) described that composites containing nano-fibrillated fiber have higher flexural strength, higher flex-ural modulus and reduced fracture energy compared to composites reinforced with conventional fiber [21]. However, a study on PHA matrix composites stated that the main limitation of PHAs in processing are their thermal instability, and mixture of nanofillers would improve its thermal stability caused by the dispersed filler layers acting as a barrier to volatiles and oxygen produced during thermal decomposition of PHAs [58]. The degree of dispersion affects the thermal degradation of nano-composites because generation of local heat as a result of accumulation.

\section{GREEN BIOCOMPOSITES MANUFACTURING}

The process of producing green biocomposites begins with the production of both natural fibers and biopolymer matrices. The compounding process of both constituents into resultant bio-composites could also influence the dispersion of fibers apart from type of natural fiber and biopolymer matrix components. It is however important to note that fiber drying is critical as the presence of moisture on the fiber surface acts as a debonding agent at the fiber-matrix interface. Significant decrease in the mechanical properties of green composites also caused by voids generated within the matrix as a result of evaporation of water during the compounding process [34]. Processing conditions and compounding process methods influence fiber dispersion, aspect ratio and orientation in biocomposites [7]. Manufacturing methods for biocomposites include open mould (hand lay-up and spray-up), and closed mould techniques such as pultrusion, extrusion, direct long-fiber thermoplastic (D-LFT), vacuum infusion, injection moulding, filament winding, resin transfer moulding, compression moulding and sheet mould compounding [7], [59]. According to Ramesh et al. (2017), compression moulding is more favorable because of the higher impact resistance of compression

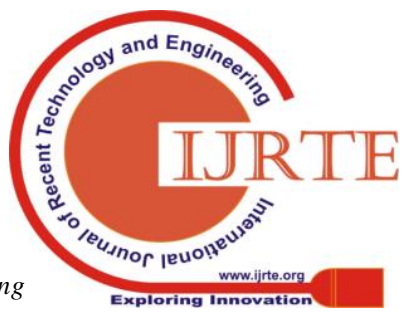


moulded parts by $50 \%$ than injection moulded ones. Another recent report mentioned that compression or explosion method for making moulded starch-based foam used in commercial food packaging helps in increasing the in-corporation between fibers and biopolymer matrix which then improve the mechanical properties of biocomposites [1]. Layer by layer technique (LBL) is another technique that can be ap-plied which permit the formation of a dense and homogeneous structure in green biocomposites and this method was utilized in a study for highly deacetylated chitosan and cellulose whiskers biocomposites as reported by Johansson et al. 2012. Melt blend-ing in preparing biocomposites is another alternative technique to produce biocomposites with unique properties. The main advantage of this technique is its lower costs due to elimination of complex processes such as polymerization reactions and purification of final products. The technique also applies avail-able components where it is performed on similar extruders in industry [60]. On the other hand, injection molding technology to produce pellet film of fiber-reinforced thermoplastic composite is illustrated in Fig.7 adopted from Tanaka (2013). Natural fiber has a low heat resistance therefore the resin temperature control during impregnation the reinforcement natural fiber is important [61].

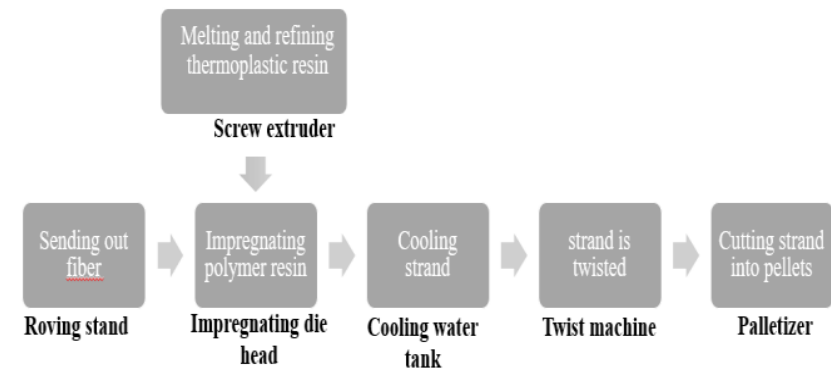

Fig. 6: Injection molding technology to produce pellet film fiber-reinforced thermoplastic composite (Tanaka, 2013)

\section{FOOD PACKAGING: MATERIALS REQUIREMENT}

Functions of food packaging are related to the physical proper-ties of the food in order to protect and preserve it, at the same time encouraging hygiene and safety [62]. Others also mentioned that food packaging also ensure food products transport-ed according to their made-to-order set-ups and amount suitable with the time they will be eaten; convenience and protected in dispensing products (easy-open features and re-closability); to add handiness to the food products; and also assist in sales increment [8], [62]. Packaging is also considered as one of the way in communicating messages to consumers and providing information and also instructions [62]. A research by Widaningrum (2014) on the elements of designing a takeout food packaging in Indonesia by using combined Conjoint Analysis and Quality Function Deployment (QFD) technique found that the 'packaging material attributes' have the highest importance values [63]. Generally, the material requirements of packaging materials are summarized in Fig. 7. These requirements are however would be exclusive for the food type to be packed where materials need to fulfil different requirement in terms of light, moisture, water vapor, and gas barriers [64]. The food package must able to obstruct gain or loss of moisture, prevent microbial contamination and represent as barrier to avoid or reduce permeation of water vapor, oxygen, carbon dioxide and other volatile compounds. In spite of this, the basic properties of packaging materials such as mechanical, optical, and thermal properties must be fulfilled first [65]. Sanyang et al. (2016) briefly summarized that suitable materials for food packaging will ensure good safety and quality of food products from processing and manufacturing stage involving handling and storage before reaching the consumers. [8].

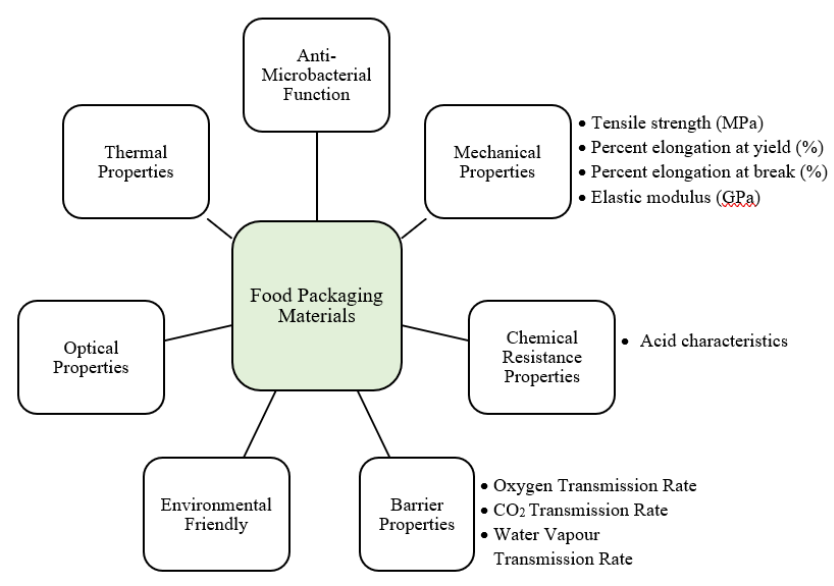

Fig. 8: General properties required for food packaging materials [10], [65].

\section{ECONOMIC IMPACT AND FUTURE DIRECTION}

A recent report stated that there were only slightly less than $1 \%$ of total global plastics production capacities for bio-based and biodegradable plastics in 2015 [66]. Furthermore, Bioplas-ticsmagazine.com analyzed a report by MarketsandMarkets on the bioplastics market and revealed that the global market for bioplastics and biopolymers reached USD 2.66 Billion in 2015 [67]. It is also said that the global bioplastics and biopolymers market is projected to represent a market value of USD 5.08 billion by 2021, a compound annual growth rate (CAGR) of 12.0\% from 2016. Additionally, a stricter environmental law globally drives this progression as bioplastics produce less negative impact on environment compared to traditional plastics. The highest market share during the forecast period is the pack-aging sector. Europe is pronounced to have the largest share of the global bioplastics and biopolymers market and is projected to remain dominating the market throughout the calculated peri-od. Meanwhile, the highest CAGR during the forecast period will be the Central and South American market due to the ready availability of feedstock in the region. Ideally, with fully biodegradable bio-based plastics, there will be zero waste out in the packaging circular system [11]. It is estimated that USD 40 billion is spent annually as the consequences of plastic packaging waste production i.e. cleansing oceans and clogging infrastructure maintenance, together with the cost associated with green-house

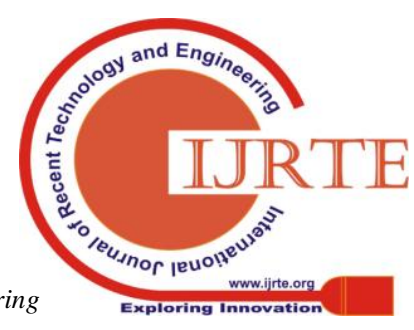


gas emissions from its production. This amount is alleged to In realizing bio-based packaging solutions, it is vital that the materials are economically feasible, and the processing method easily be adapted in the existing industrial manufacturing processes [7]. The economic production of development of biotechnological processes [68]. The cost and performance of green biocomposites materials must be addressed to flourish the use of these renewable materials in packaging industry. Other major concerns of the industry players are the effective, secure, and long-lasting supplies of raw materials. Johansson et al. (2017) specifically highlighted three main challenges of green biocomposites that are; 1) sustainability of raw material productions, 2) environmentally friendly process of extraction/ purification to iso-late natural fibers and production of uniform quality fiber for further enhancement into packaging products application, and 3) target of applications and; new value and unique properties to natural fiber through chemical modification or development of nano-scaled materials [7]. It is important to note that the increasing demand of natural fiber and biopolymer would generate an industrial crop source which could upgrade the rural and agriculture-based communities economically. The issues of socio-economic such as poverty and employment deficient could be addressed. People will get opportunities to learn advanced methods and skills to produce reinforcement fiber and biopolymer resin. Production of intermediate supplies could be distributed to high-technology engineering companies for commercial composites manufacturing. Locally manufactured biocomposites could then be developed and involved in the supply chain of 'green' packaging products [22].

\section{CONCLUSIONS}

Green biocomposites for food packaging materials sure have high potential to replace conventional non-biodegradable plastics. Nevertheless, their inadequate mechanical and barrier properties restrain them from being used extensively in food packaging industry for the time being. Numerous methods are studied and being developed continuously to further enhance the performance properties of these material including surface modification, and application of nano-technology to produce bio-nanocomposites. Manufacturing techniques too need to be more efficient with less energy usage. Techniques that can easily adapt with present industrial manufacturing processes would be the best to get industry players' interest. Apart from green biocomposites performance as the key obstacles for packaging application, raw material cost and consistent supply are another major concern in a larger scale of economy. The business mind-setting and risk-taking ventures to materialize Circular Packaging System with zero waste out will create new opportunities for business and its supply chain. Assistance, guidance and supports from all stakeholders in producing fully bio-based and biodegradable materials of green biocomposites will eventually give sustainable impacts on the growth of socio-economy of the has exceeded the plastic packaging industry's profit pool [6]. biopolymers is however very much reliant on the

\section{ACKNOWLEDGMENT}

The authors wish to express highest appreciation to the Public Service Department (JPA), Malaysia for the study sponsorship to the main author, and financial support in this study from the Ministry of Education Malaysia through Universiti Putra Malaysia Grant Scheme High Centre of Excellence (HICoE) (6369107). Thank you for continuous encouragement and support from Ministry of Youth and Sports Malaysia, previous employer of the main author.

\section{REFERENCES}

1. Y. Su et al., "Prospects for Replacement of Some Plastics in Packaging with Lignocellulose Materials: A Brief Review," BioResources, vol. 13, no. 2, Feb. 2018.

2. A. Soroudi and I. Jakubowicz, "Recycling of bioplastics, their blends and biocomposites: A review," Eur. Polym. J., vol. 49, no. 10, pp. 2839-2858, 2013.

3. R. Geyer, J. R. Jambeck, and K. L. Law, "Production, uses, and fate of all plastics ever made," Sci. Adv., vol. 3, no. 7, p. 5, 2017.

4. L. D. Nguyen, "An Assessment of Policies on Polystyrene Food Ware Bans An Assessment of Policies on Polystyrene Food Ware Bans," 2012

5. K. Majeed et al., "Potential materials for food packaging from nanoclay/natural fibres filled hybrid composites," Materials and Design, vol. 46. Elsevier, pp. 391-410, 01-Apr-2013.

6. Ellen MacArthur Foundation, "The New Plastics Economy: Rethinking the future of plastics," World Econ. Forum New Plast. Econ., no. January, p. 120, 2016.

7. C. Johansson et al., "RENEWABLE FIBERS AND BIO-BASED MATERIALS FOR Packaging Applications - A Review of Recent Developments," Bioresources, vol. 7, no. 2, pp. 1-47, 2012.

8. M. L. Sanyang, R. A. Ilyas, S. M. Sapuan, and R. Jumaidin, "Sugar Palm Starch-Based Composites for Packaging Applications," in Bionanocomposites for Packaging Applications, Cham: Springer International Publishing, 2018, pp. 125-147.

9. F. M. Al-oqla and M. A. Omari, Green Biocomposites. Cham: Springer International Publishing, 2017.

10. V. Siracusa, P. Rocculi, S. Romani, and M. D. Rosa, "Biodegradable polymers for food packaging: a review," Trends in Food Science and Technology, vol. 19, no. 12. Elsevier, pp. 634-643, 01-Dec-2008.

11. B. de Koeijer, R. Wever, and J. Henseler, "Realizing Product-Packaging Combinations in Circular Systems: Shaping the Research Agenda," Packag. Technol. Sci., vol. 30, no. 8, pp. 443-460, 2017.

12. K. Majeed et al., "Potential materials for food packaging from nanoclay/natural fibres filled hybrid composites," Mater. Des., vol. 46, pp 391-410, 2013

13. M. L. Sanyang, M. R. Mansor, S. M. Sapuan, and B. A. Ahmed Ali, "Conceptual design of biocomposites for automotive components," Green Energy Technol., no. 9783319493817, pp. 101-126, 2017.

14. M. L. Sanyang, S. M. Sapuan, M. Jawaid, M. R. Ishak, and J. Sahari, "Effect of plasticizer type and concentration on physical properties of biodegradable films based on sugar palm (arenga pinnata) starch for food packaging," J. Food Sci. Technol., vol. 53, no. 1, pp. 326-336, 2016.

15. F. M. Al-Oqla and A. A. Omar, "An expert-based model for selecting the most suitable substrate material type for antenna circuits," Int. J. Electron., vol. 102, no. 6, pp. 1044-1055, 2015.

16. T. Mukherjee and N. Kao, "PLA Based Biopolymer Reinforced with Natural Fibre: A Review," J. Polym. Environ., vol. 19, no. 3, pp. 714-725, Sep. 2011.

17. N. Saba, M. Jawaid, M. T. H. Sultan, and O. Y. Alothman, "Green Biocomposites for Structural Applications,” M. Jawaid, M. S. Salit, and O. Y.Alothman, Eds. Springer, 2017, pp. 1-27.

18. S. M. Sapuan, Materials Selection for Composites: Concurrent Engineering Perspective, vol. 219. 2017.

19. M. R. Mansor, M. S. Salit, and E. S. Zainudin, "Life Cycle Assessment of Natural Fiber Polymer Composites," 2015

20. B. C. Mitra, "Environment friendly composite materials: Biocomposites and green composites," Def. Sci. J., vol. 64, no. 3, pp. 244-261, 2014.

21. M. Ramesh, K. Palanikumar, and K. H. Reddy, "Plant fibre based bio-composites: Sustainable and renewable green materials," Renewable and Sustainable Energy Reviews, vol. 79, no. February. 
Elsevier Ltd, pp. 558-584, 2017.

22. J. Sahari, S. M. Sapuan, E. S. Zainudin, and M. A. Maleque, "Mechanical and thermal properties of environmentally friendly composites derived from sugar palm tree," Mater. Des., vol. 49, pp. 285-289, 2013.

23. Y. Dong, A. Ghataura, H. Takagi, H. J. Haroosh, A. N. Nakagaito, and K. T. Lau, "Polylactic acid (PLA) biocomposites reinforced with coir fibres: Evaluation of mechanical performance and multifunctional properties," Compos. Part A Appl. Sci. Manuf., vol. 63, pp. 76-84, 2014.

24. M. A. Berthet et al., "Exploring the potentialities of using lignocellulosic fibres derived from three food by-products as constituents of biocomposites for food packaging," Ind. Crops Prod., vol. 69, pp. 110-122, 2015.

25. M. P. Arrieta, J. López, D. López, J. M. Kenny, and L. Peponi, "Effect of chitosan and catechin addition on the structural, thermal, mechanical and disintegration properties of plasticized electrospun PLA-PHB biocomposites," Polym. Degrad. Stab., vol. 132, pp. 145-156, 2016.

26. N. S. Santos, M. R. Silva, and J. L. Alves, "Reinforcement of a biopolymer matrix by lignocellulosic agro-waste," in Procedia Engineering, 2017, vol. 200, pp. 422-427.

27. R. Jumaidin, S. M. Sapuan, M. Jawaid, M. R. Ishak, and J. Sahari, "Thermal, mechanical, and physical properties of seaweed/sugar palm fibre reinforced thermoplastic sugar palm Starch/Agar hybrid composites," Int. J. Biol. Macromol., vol. 97, pp. 606-615, 2017.

28. O. Ochoa-Yepes, C. Medina-Jaramillo, L. Guz, and L. Famá, "Biodegradable and Edible Starch Composites with Fiber-Rich Lentil Flour to Use as Food Packaging," Starch/Staerke, 2018.

29. E. L. Sánchez-Safont, A. Aldureid, J. M. Lagarón, J. Gámez-Pérez, and L. Cabedo, "Biocomposites of different lignocellulosic wastes for sustainable food packaging applications," Compos. Part B Eng., vol. 145, pp. 215-225, 2018.

30. S. Qian, H. Zhang, W. Yao, and K. Sheng, "Effects of bamboo cellulose nanowhisker content on the morphology, crystallization, mechanical, and thermal properties of PLA matrix biocomposites," Compos. Part B Eng., vol. 133, pp. 203-209, 2018

31. X. Z. Tang, P. Kumar, S. Alavi, and K. P. Sandeep, "Recent Advances in Biopolymers and Biopolymer-Based Nanocomposites for Food Packaging Materials," in Critical Reviews in Food Science and Nutrition, vol. 52, no. 5, V. K. Thakur, M. K. Thakur, and M. R. Kessler, Eds. Hoboken, NJ, USA: John Wiley \& Sons, Inc., 2017, pp. 426-442.

32. A. A. Singh, S. Afrin, and Z. Karim, "Green Composites: Versatile Material for Future," in Green Energy and Technology, no. 9783319493817, 2017, pp. 29-44.

33. N. Saba, M. Jawaid, and O. Al-Othman, "An Overview on Polylactic Acid, its Cellulosic Composites and Applications," Curr. Org. Synth., vol. 14 no. 2 , pp. 156-170, Feb. 2017

34. R. Siakeng, M. Jawaid, H. Ariffin, and S. M. Sapuan, "Physical properties of coir and pineapple leaf fibre reinforced polylactic acid hybric composites," IOP Conf. Ser. Mater. Sci. Eng., vol. 290, p. 012031, Jan. 2018.

35. G. Aminosilane, "Reinforcing Mechanical, Water Absorption and Barrier Properties of Poly ( Lactic Acid ) Composites with Kenaf-Derived Cellulose of Thermally- Reinforcing Mechanical, Water Absorption and Barrier Properties of Poly ( Lactic Acid ) Composites with Kenaf-D," no. January, 2016

36. V. Siracusa, P. Rocculi, S. Romani, and M. D. Rosa, "Biodegradable polymers for food packaging: a review," Trends Food Sci. Technol., vol. 19 , no. 12 , pp. 634-643, 2008

37. M. J. Fabra, A. López-Rubio, J. Ambrosio-Martín, and J. M. Lagaron, "Improving the barrier properties of thermoplastic corn starch-based films containing bacterial cellulose nanowhiskers by means of PHA electrospun coatings of interest in food packaging," Food Hydrocoll., vol. 61, pp. 261-268, 2016

38. L. Ren, X. Yan, J. Zhou, J. Tong, and X. Su, "Influence of chitosan concentration on mechanical and barrier properties of corn starch/chitosan films," Int. J. Biol. Macromol., vol. 105, pp. 1636-1643, 2017.

39. M. J. Fabra, A. Lopez-Rubio, and J. M. Lagaron, "Nanostructured interlayers of zein to improve the barrier properties of high barrier polyhydroxyalkanoates and other polyesters," J. Food Eng., vol. 127, pp. $1-9,2014$

40. M. S. Sapuan, Tropical Natural Fibre Composites: Properties, Manufacture and Applications. SPRINGER, 2014.

41. S. M. Sapuan, J. Y. Kho, E. S. Zainudin, Z. Leman, B. a Ahmed Ali, and A. Hambali, "Materials selection for natural fiber reinforced polymer composites using analytical hierarchy process," Indian J. Eng. Mater. Sci., vol. 18, no. August, pp. 255-267, 2011.

42. F. M. Al-Oqla, M. S. Salit, M. R. Ishak, and N. A. Aziz, "Selecting natural fibers for bio-based materials with conflicting criteria," Am. J. Appl. Sci., vol. 12 , no. 1 , pp. $64-71,2015$

43. M. L. Sanyang, S. M. Sapuan, M. Jawaid, M. R. Ishak, and J. Sahari, "Effect of sugar palm-derived cellulose reinforcement on the mechanical and water barrier properties of sugar palm starch biocomposite films," BioResources, vol. 11, no. 2, pp. 4134-4145, 2016.

44. M. F. M. Alkbir, S. M. Sapuan, A. A. Nuraini, and M. R. Ishak, "Fibre properties and crashworthiness parameters of natural fibre-reinforced composite structure: A literature review," Composite Structures, vol. 148 pp. 59-73, 2016.

45. M. R. M. Huzaifah, S. M. Sapuan, Z. Leman, and M. R. Ishak, "Comparative Study on Chemical Composition, Physical, Tensile, and Thermal Properties of Sugar Palm Fiber (Arenga pinnata) Obtained from Different Geographical Locations," bioresources.com, vol. 12, no. 4, pp. 9366-9382, 2017

46. M. R. M. Huzaifah, S. M. Sapuan, Z. Leman, and M. R. Ishak, "Comparative study on chemical composition, physical, tensile, and thermal properties of sugar palm fiber (Arenga pinnata) obtained from different geographical locations," BioResources, 2017.

47. M. S. Salit, "Manufacturing Techniques of Tropical Natural Fibre Composites," 2014, pp. 103-118.

48. F. M. AL-Oqla, M. S. Salit, F. M. AL-Oqla, and M. S. Salit, "4 - Material selection for composites," in Materials Selection for Natural Fiber Composites, 2017, pp. 73-105.

49. K. S. Chun and S. Husseinsyah, "Comparison study on green coupling agents from different type of plants oil for agrowaste-based thermoplastic composites," J. Thermoplast. Compos. Mater., vol. 30, no. 7, pp. 938-949, 2017

50. Y. Zhou, M. Fan, and L. Lin, "Investigation of bulk and in situ mechanical properties of coupling agents treated wood plastic composites," Polym. Test., vol. 58, pp. 292-299, 2017.

51. J. Cruz and R. Fangueiro, "Surface Modification of Natural Fibers: A Review," Procedia Eng., vol. 155, pp. 285-288, 2016.

52. L. Sisti, G. Totaro, M. Vannini, and A. Celli, "Retting Process as a Pretreatment of Natural Fibers for the Development of Polymer Composites," in Lignocellulosic Composite Materials, 2018, pp. 97-135.

53. C. Dicke, C. Lühr, R. Ellerbrock, J. Mumme, and J. Kern, "Effect of hydrothermally carbonized hemp dust on the soil emissions of $\mathrm{CO}<\inf >2</ \inf >$ and $\mathrm{N}<\inf >2</ \inf >0$," BioResources, vol. 10, no. 2, pp. $3210-3223,2015$

54. A. H. Bhat, Y. K. Dasan, I. Khan, and M. Jawaid, "Cellulosic biocomposites: Potential materials for future," Green Energy Technol., no 9783319493817, pp. 69-100, 2017.

55. M. T. Mastura, S. M. Sapuan, M. R. Mansor, and A. A. Nuraini, "Environmentally conscious hybrid bio-composite material selection for automotive anti-roll bar," Int. J. Adv. Manuf. Technol., vol. 89, no. 5-8, pp 2203-2219, 2017.

56. R. A. Ilyas, S. M. Sapuan, and M. R. Ishak, "Isolation and characterization of nanocrystalline cellulose from sugar palm fi bres ( Arenga Pinnata )," Carbohydr. Polym., vol. 181, no. October 2017, pp. 1038-1051, 2018.

57. K. Khosravi-Darani, "Application of Poly(hydroxyalkanoate) In Food Packaging: Improvements by Nanotechnology," Chem. Biochem. Eng. Q. vol. 29, no. 2, pp. 275-285, 2015

58. M. N. Akhtar et al., "Kenaf-Biocomposites: Manufacturing, Characterization, and Applications," in Green Energy and Technology, no. 9783319466095, 2017, pp. 225-254.

59. K. Formela, A. Hejna, J. Haponiuk, and A. Tercjak, In situ processing of biocomposites via reactive extrusion. Report No: NWS-E-2009-32. Elsevier Ltd., 2017.

60. T. Tanaka and H. Ito, "Manufacturing and Processing Methods of Biocomposites," in Polymer Composites, Weinheim, Germany: Wiley-VCH Verlag GmbH \& Co. KGaA, 2013, pp. 179-211.

61. F. Fernqvist, A. Olsson, and S. Spendrup, "What's in it for me? Food packaging and consumer responses, a focus group study," Br. Food J., vol 117, no. 3, pp. 1122-1135, 2015.

62. D. L. Widaningrum, "The Importance of Take-Out Food Packaging Attributes : Conjoint Analysis and Quality Function Deployment Approach," EPJ Web Conf., vol. 36, no. 68, pp. 1-7, 2014

63. E. Bugnicourt et al., "Processing and validation of whey-protein-coated films and laminates at semi-industrial scale as novel recyclable food packaging materials with excellent barrier properties," Adv. Mater. Sci. Eng., vol. 2013, pp. 5-7, 2013

64. J.-W. Rhim, H.-M. Park, and C.-S. Ha, "Bio-nanocomposites for food packaging applications," Prog. Polym. Sci., vol. 38, no. 10-11, pp. $1629-1652,2013$

65. M. van den Oever, K. Molenveld, M. van der Zee, and H. Bos, "Bio-based and biodegradable plastics - Facts and Figures - Focus on food packaging in the Netherlands," 2017.

66. bioplasticsmagazine.com, "MarketsandMarkets projects $12 \%$ annual growth bioplastics market through 2021," Polymedia Publisher GmbH, Mönchengladbach Germany, p.

\section{Published By:}

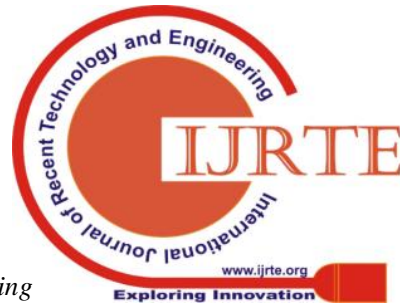

Eves Intelligence Engineering $\&$ Sciences Publication 
20160639, Jun-2016.

67. S. Y. Lee, S. J. Park, J. P. Park, Y. Lee, and S. H. Lee, "Economic Aspects of Biopolymer Production," in Biopolymers Online, A. Steinbüchel, Ed. Weinheim, Germany: Wiley-VCH Verlag GmbH \& Co. KGaA, 2005.

68. S. M. Sapuan, Composites Materials: Concurrent Engineering Approach. oxford: Butterworth-Heinemann Elsevier Inc., 2017.

\section{AUTHORS PROFILE}

S.M. Sapuan Professor of composite materials at Universiti Putra Malaysia and has a $\mathrm{PhD}$ from De Montfort University, UK in 1998 and MSc from Loughborough University, UK in 1994. His research interests include natural fiber composites, materials selection and concurrent engineering. To date he has published more than 650 journal and 550 conference papers, 15 books, 17 edited books and 108 chapters in book. He is a Fellow of Society of Automotive Engineers, International, USA, Fellow, Institute of Materials Malaysia, Fellow, Malaysian Scientific Association, Fellow, Plastics and Rubber Institute Malaysia (PRIM) and Honorary Member of Asian Polymer Association. He has received numerous awards and honours, among others, ISESCO Science Prize in Technology, 2008, PRIM Fellowship Award, Kuala Lumpur Rotary Research Gold Medal Award, Alumni Award, University of Newcastle, NSW, Australia, Khwarizmi International Award (KIA), a Leadership Award from Society of Automotive Engineers International (SAE) i.e. SAE Fellow Grade of membership, 2015/2016 grantee of SEARCA Regional Professorial Chair, Endeavour Research Promotion Award, IEEE India, Citation of Excellence 2017, Emerald UK, National Book Awards 2017 and 2018 and Malaysia's Research Star Award.

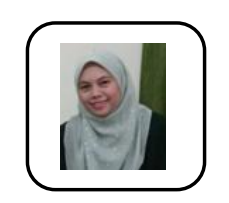

H.N. Salwa PhD student at Institute of Tropical Forestry and Forests Product (INTROP), Universiti Putra Malaysia (UPM) and her research is on design for sustainability with the potential of green biocomposites utilization for food packaging. Holds MSc. in Product Design Innovation from Aston University, Birmingham.

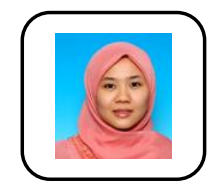

M.T. Mastura $\mathrm{PhD}$ in Mechanical Engineering from Universiti Putra Malaysia. Her area of interest includes natural fibre composites, material selection and concurrent engineering and actively published papers in related area.

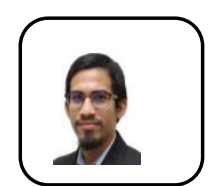

M.Y.M Zuhri $\mathrm{PhD}$ in Composite Materials from University of Liverpool currently a senior lecturer in Department of Mechanical and Manufacturing Engineering, Universiti Putra Malaysia (UPM). His areas of interest are in composite materials and lightweight structures. To date, he has authored and coauthored more than 20 papers including journal and conference papers. 